CHRONIC STRUCTURAL LOW BACKACHE DUE TO LOW-BACK STRUCTURAL DERANGEMENT

By R. A. Roberts, B.Sc., M.B., Ch.B., D.M.G.E.

(H. K. Lewis and Co. London. 1947. Pp. 98. 137 illustrations. Price 45s.)

This book provides a graphic description of low backache and its management, particularly under service conditions. There is emphasis on faulty recognition of possible causes of low back symptoms due to abnormalities in the bony skeleton of the lumbar region, and very frank and open criticism of the psychiatric diagnosis of "low back pain-anxiety neurosis." The author stresses the importance of defects in ossification in the region of the neural arch known as the "pars-interarticularis," and points out the necessity for oblique views in carrying out the radiographic investigation. Seven groups of defects are discussed, with illustrative case reports, and accompanying $x$-ray pictures and/or tracings.

The defects described are not congenital in origin, and the stress and strain of the erect posture on the pars-interarticularis, rather than definite trauma (fracture), frequently results in symptoms occurring in early life (two-thirds of the cases). The defect is described as a deficiency in ossification, though in some cases there is a picture closely resembling the " march facture" type of reaction.

For purposes of diagnosis a plea is made for more frequent routine spinal radiography, particularly in women, and for re-assessment of differential diagnosis. In the way of treatment the author favours local spine fusion, both anteriorly in the adjacant vertebral body margins, and posteriorly in the paravertebral joints, but he also points out that when there is an incipient back weakness, graduated rehabilitation and careful choice of occupation are essential. To all medical men who are frequently faced with the problem of diagnosis of "low back pain," the book will be of interest, and particularly for information in $x$-ray interpretation. It should make them realize that very thorough investigation must be made in every case before a "functional " label be attached, for after all, the psychiatrist has the right to expect that he is called into consultation when organic disease has been excluded, or when there is a functional overlay in addition to organic disease.

There is an excellent list of references and a good index at the end of the volume, which is excellently printed, with clear illustrations.

W. A. L.

\section{TREATISE ON THE CHARACTERISTICS AND SILICOSIS HAZARD OF ROCKS AND THEIR INGREDIENTS FOUND IN GERMAN MINES}

By W. Landwehr

English Translation by M. C. S. Kennedy

(W. Girardet. Essen. 1947. Pp. 286. No price given.)

This book, which is well illustrated, is a study from a petrological point of view of the various rocks and ores encountered in the German mines. Three thousand different rocks were investigated, and studies were made of the distribution of quartz, feldspar, sericite, clay, ore, coal, and carbonate in these rocks, and a fraction of the bore dust containing particles of less than $42 \mu$. The author considers that the harder the rock the greater is the percentage of the bore dust under $42 \mu$ and the more likely are changes in the lung. These changes are also more likely if there is a high percentage of quartz in the finest bore, while as the percentage of calcium carbonate increases the danger decreases. From these considerations he has derived figures which indicate the degree of danger of lung changes which might be expected from any given bore dust. It is a stimulating treatise worthy of study, and Dr. Kennedy is to be congratulated on his efforts to achieve its publication.

K. M. A.P.

BREATHING IN IRRESPIRABLE ATMOSPHERES
By Sir Robert H. Davis
(The Saint Catherine Press. London. 1947. Pp. 386.
Price 25s.)
This book, which is to some extent an advertisement for Siebe Gorman and Co. Ltd., is also an authoritative and comprehensive account of all that appertains to overcoming the problems of breathing under harmful conditions. For those interested in this subject it is an extremely valuable book. The first chapter, an historical review of the development of poison gas and incendiary warfare, is followed by a chapter on the physiology of respiration. A full account is then given of respiration at high altitudes, apparatus used in the Mount Everest expedition and on the pioneer flights at high altitudes being described. Methods of resuscitation are discussed. All modern gas-masks are illustrated; and modern breathing appliances which may be used in warfare, mines, sewers, chemical works, and gas works, and by fire brigades and divers under water, are all described. Mine rescue and recovery work after disasters are discussed, and there are descriptions and illustrations of the Rescue Brigades' training methods and accounts of some of their life-saving and recovery operations.

K. M. A.P.

\section{PSYCHOLOGY IN INDUSTRY}

By Norman R. F. Maier

(George G. Harrap and Co. Ltd. London. 1947. Pp. 463. Price 12s. 6d.)

Although it is generally accepted that the science of psychology has much to contribute towards the successful and harmonious working of the industrial machine, practical use of it is still confined to a minority of business organizations. Indeed, it is not unfair to say that the average business man in this country has little knowledge of it. For him, as well as for the student of psychology, Doctor Maier's book offers a simple and clear exposition of an intricate subject. It deals among other things with the application of psychological principles to the relationship between employer and employee, to questions of morale, motivation, and fatigue, and to the use of psychological tests in assessing ability. In an interesting and original chapter on accidents and their prevention the causes of accident-proneness are analysed and promising methods of tackling this problem suggested. The material is attractively presented with a notable absence of difficult technical detail, which makes it easy reading for anybody who is not himself an industrial psychologist. The book can be recommended to those whose lot it is to direct the activities of their fellow men and who at the same time are interested in promoting the smooth interactions of the group under their control. T. D. P 